\title{
Uma reflexão crítica sobre a prática científica e o seu contributo para a qualidade de vida da sociedade
}

\author{
A critical reflection about the scientific practice and its contribution to \\ the quality of life of the society
}

\section{J. Vasconcelos-Raposo, C.M. Teixeira, H.M. Fernandes}

O crescente ritmo a que atualmente o conhecimento é acumulado não tem reflexo na melhoria da qualidade de vida dos povos, em geral. Na realidade, em alguns casos, os progressos têm servido para reforçar a ideia, crescente nos tempos que correm, que os seres humanos não são valorizados por essa condição (a de serem Humanos), mas sim por outros artifícios culturais, nomeadamente a capacidade financeira que têm. Esta é uma constatação que se faz sentir de forma muito particular na área da saúde.

O objetivo nobre da ciência tem sido, ao longo dos tempos, apresentado como sendo o de explicar os fenómenos e assim contribuir para a melhoria de vida da Humanidade. Mas, na realidade, a prática científica tem vindo a ser promovida com um enfoque práxico que, de alguma forma, é condicionador do comportamento daqueles que investigam, uma vez que tende a privilegiar aspetos que encontram pouco eco no bem-estar coletivo, mas sim nos que promovem a competição entre aqueles que deveriam cooperar para produzir melhor ciência e com maior relevância sociocultural. São encorajados e financiados, fundamentalmente, as áreas de pesquisa onde se podem identificar novos produtos a serem industrializados, ou seja, capazes de gerar mais-valias. É neste quadro que nos propomos a apresentar uma reflexão crítica sobre a forma como alguns ganhos têm sido integrados na vida de todos nós. Tomaremos como ponto de partida o que nos é dado a observar no caso dos tratamentos de alguns tipos de cancro.

Ninguém contesta que a investigação na área dos estudos do cancro tem produzido ganhos fantásticos, especialmente no que se refere às intervenções terapêuticas através de novos fármacos. Acontece, porém, que estes, apesar de serem financiados pelas populações em geral, através dos seus impostos, só estão disponíveis para os que têm uma capacidade financeira diferenciada na acumulação de capital. Quem mais tem, melhor tratamento recebe. Aos olhos dos que se inspiram numa ideologia neoliberal nada emerge de estranho nesta prática: é a lei do mercado. Porém, para quem recorre a análises um pouco mais ricas, por serem de natureza interdisciplinar, tal diferença não deveria existir, e o argumento economicista não é mais que a evidência de uma capacidade limitada de processar informação que vá para além do ganho imediato que o EU deseja ter. A evidenciá-lo está o fato de na crise que atualmente os países enfrentam, como sequência de más práticas da banca, se considere normal e até exigível que os Estados (todos os cidadãos e que nada fizeram para que a crise tivesse lugar) tenham de estar a financiar a recapitalização desses bancos que continuam a acumular lucros a um ritmo interessante. Seria de esperar que os que defendem a diferença no acesso diferenciado dos medicamentos erguessem a voz contra o apoio do Estado aos bancos e aos empresários falidos.

José Vasconcelos-Raposo e Helder Miguel Fernandes. Direção da Revista Motricidade; Universidade de Trás-os-

Montes e Alto Douro, Vila Real, Portugal.

Carla Maria Teixeira. Universidade de Trás-os-Montes e Alto Douro, Vila Real, Portugal.

E-mail: editor.motricidade@gmail.com 
Mas esta é uma discussão política à qual a ciência não se deve manter alheia. Caso contrário, o produto da investigação é um bem desvalorizado enquanto ciência, para ser reconhecido e apreciado apenas quando transformado em riqueza. O posicionamento acrítico da comunidade científica permite que os pesquisadores vivam alienados das realidades socioculturais onde desenvolvem as suas atividades. Quando nos mantemos acríticos permitimos que atrocidades sejam cometidas em nome da ciência, tal como a história recente na área da saúde nos demonstrou aproximadamente 70 anos atrás, tanto na Europa, como na Ásia. Toda a prática científica não se deve alhear da dimensão humana, pois fazê-lo é, direta ou indiretamente, legitimar a violação grosseira de alguns direitos humanos básico, como é o caso da saúde.

$\mathrm{O}$ atual paradigma da produtividade científica é, por si só, uma contradição. Por um lado, fazem-se apelos aos estudos interdisciplinares e por outro lado, quando se fazem as avaliações curriculares aqueles que tenderam a aderir a essa prática acabaram sendo prejudicados. De qualquer forma, estamos convictos que encorajar a pesquisa inter e multidisciplinar é uma forma eficaz de promover a capacidade de pensamento crítico e talvez por essa razão esses pensadores tendam a estar em maior sintonia com as realidades socioculturais e as condições de vida das pessoas que, em princípio, devem beneficiar da acumulação do conhecimento científico.

Uma investigação científica orientada para a defesa e promoção da condição humana deverá ter por base todos os aspetos que de uma forma ou outra se fazem repercutir no dia-a-dia de cada um. Tal como conhecemos a ciência, assim como a forma como formamos os cientistas, não iremos longe nos avanços a serem feitos no que diz respeito à qualidade de vida das populações. Apenas uma prática científica que combine saberes possibilita dar respostas às complexidades em causa. Mas uma sociedade em que os próprios "Homens" da ciência, por questões de vaidades pessoais se deixam envolver numa prática, intelectualmente menor, de dividir os ramos da ciência em áreas científicas mais prestigiadas que outras, pouco tem a esperar destes pensadores, pois perdemse a olhar e a falar de uma árvore como se fosse uma planta ornamental de um jardim qualquer, quando na realidade é de uma floresta imensa.

Para esclarecer este aspeto tenhamos por referência dois domínios científicos que tem por objeto de intervenção a mesma unidade, mas em perspetivas diferentes: A Educação Física e a Medicina. Ambos têm o Homem como objeto de trabalho; no entanto, a primeira tem por meta a autonomia e a capacidade de trabalho educando que, em parte, a cada um que cabe a responsabilidade pela preservação do seu estado de saúde, assim como também de todos os que com ele constituem a comunidade onde vivem. Para a medicina, a intervenção é de outro tipo, pois tem por intenção nobre curar e restituir a saúde. A diferenciar estas duas temos que a Educação Física, para ser bem-sucedida requer um envolvimento ativo e persistente de cada um, enquanto na prática da medicina esse mesmo sucesso requer que o indivíduo abdique da sua liberdade de decidir, em favor do médico.

Talvez como consequência do processo de evolução da espécie, os Homens tendam a favorecer, nas suas análises e consequentes juízos, os aspetos negativos com que se deparam no seu dia-a-dia. Por exemplo, sempre que algum tipo de incerteza é vivenciado pelo Homem, o organismo disponibiliza um conjunto de substâncias de forma a permitir uma resposta perante a eventual ameaça. Podemos mesmo aceitar que há uma certa predisposição genética para privilegiar o negativo em detrimento do positivo. Porém, essa forma de pensar implica, também, reconhecer que valorizar os eventos positivos dá lugar a uma forma mais complexa de estar e que esta, por sua vez, resulta de processos como os da enculturação (aprendizagem da primeira cultura) e socialização (aprendizagem das normas que regulamentam a interação entre indivíduos, grupos e instituições). É exatamente essa dimensão cultu- 
ral do Homem que serve de alicerce à valorização do que se faz da ciência. Mas na última instância, sempre que na forma de confronto entre a forma básica de estar na vida e aquela que é mais consonante com a própria evolução da espécie (o criar cultura), há um número vastíssimo de Homens que não vai além da resposta simplista da genética e isso, na sociedade atual resulta no favorecer o que dá lucro. Assim, a Educação Física promove o mais nobre da Humanidade, as práticas culturais, preferencialmente tal como se enquadram no meio ambiente, ou que a tentam imitar, embora estas tendem a não ser profissionalmente valorizadas apesar de serem as mais diretamente responsáveis pelos ganhos em anos de vida que se têm verificado. Porém, esse mesmo Homem, quando confrontado com a finitude da sua existência procura ajuda e aquela que lhe é prestada é sobrevalorizada. Mas mesmo assim, após o período de doença, e apesar de serem os médicos a recomendarem mudanças do estilo de vida e que devem deixar de fumar, beber, devem ser fisicamente ativos, etc., continuam sem valorizar o que é a importância efetiva da Educação Física. Neste caso, esse reconhecimento já não se deve ao desconhecimento mas sim à eventual necessidade de manter uma "narrativa de vida" coerente e assim manter uma aparente saúde mental.

Mas olhemos de forma mais detalhada às posturas profissionais e às decisões relativas às políticas de saúde pública: o caso do cancro.

Há um crescimento do número de cancros a cada ano que passa. Mas isto é consequência, fundamentalmente, do fato de que as pessoas vivem mais tempo. Quantos mais anos os indivíduos vivem, maiores as probabilidades de lhes ser diagnosticado um cancro tendo por base o que naturalmente ocorre ao nível biológico, com as alterações que inevitavelmente ocorrem ao nível do DNA celular. Tem sido ao nível das alterações celulares que se têm verificado grandes progressos no que se refere à capacidade de intervenção terapêutica. Mas importa destacar um outro tipo de resultados da pesquisa que, por não estar centrado no negativo que é a doença em si, não tem merecido a atenção que deveria ter: o exercício físico.

A investigação científica tem evidenciado que uma larga percentagem dos casos de cancro está associada a estilos de vida. De acordo com a Encyclopedia of Cancer, Vol. 1, as mais recentes evidências epidemiológicas demonstram, de forma inequívoca, que alguns cancros, nomeadamente os de pulmão, colo-rectal, próstata e da mama, que no seu conjunto são responsáveis por mais de $50 \%$ dos cancros diagnosticados no mundo ocidental, estão intimamente associados aos hábitos comportamentais. Assim, o consumo de tabaco causa cerca de $30 \%$ dos cancros, a inatividade física explica $5 \%$, a obesidade associa-se a $15 \%$, a dieta a $10 \%$, as bebidas alcoólicas a $5 \%$ e a exposição excessiva ao Sol 3\%. Colditz, o editor desta enciclopédia, argumenta que face a este conhecimento $50 \%$ dos cancros podem ser prevenidos, uma vez que estão associados a comportamentos que podem ser mudados.

Ao aceitarmos estes resultados, torna-se evidente, pelo menos para alguns, que é urgente repensar algum do investimento que é feito na saúde, ou se quisermos nos domínios da Educação e Promoção para a Saúde. Não é suficiente reconhecer que é necessário que as pessoas mudem os seus comportamentos. Importa saber quais os motivos presentes que levam os indivíduos a serem resistentes a essas alterações no comportamento. Esta é uma área de intervenção profissional que requer alguns cuidados, mas que infelizmente continua negligenciada nos sistemas de ensino. Parecenos inadequado continuar a insistir num modelo que após décadas de aplicação se tem demonstrado ineficaz em garantir as mudanças necessárias, se é que efetivamente se desejam essas alterações. É um erro continuar a colocar no terreno, pessoas treinadas técnica e cientificamente para intervirem no processo de prestação de cuidados médicos, para fazer educação e promoção para a saúde. Uma das poucas áreas de formação para intervir nestes domínios é o da Psicologia do Exercício e Saúde que 
expande a intervenção psicoterapêutica, recorrendo ao exercício físico como mais uma ferramenta para intervir no processo de alívio de sintomas, tal como se faz recorrendo à farmacologia, e promovendo as mudanças comportamentais e estilos de vida, o que lhe confere um estatuto único nos domínios científicos da saúde.

É inquestionável que a atividade física é promotora de saúde. Uma política de saúde de cariz preventivo, decerto que deveria ter em atenção as medidas que pudessem, concomitantemente, promover os níveis de saúde e poupanças nos gastos que o Estado tem na oferta centrada numa medicina curativa. Por exemplo, a promoção da atividade física regular, devidamente prolongada no tempo e supervisionada por profissionais devidamente treinados na área da promoção de mudanças ao nível do indivíduo como um TODO (mente e corpo), no mínimo, contribuiria com uma redução de aproximadamente $20 \%$ dos casos de cancro. Os restantes $30 \%$ poderiam ser alvo de programas adequadamente desenvolvidos por psicólogos. Neste caso, os profissionais especializados em Psicologia do Exercício e da Saúde apresentam vantagens sobre as restantes áreas de intervenção mais tradicionais ou convencionais, dada a conjugação de saberes e competências nestes domínios de intervenção.

Para uns, esta proposta é certamente utópica, na medida em que no presente não se deslumbram entidades políticas e financiadoras sensibilizadas para esta forma de intervenção. Porém, com base no conhecimento que temos da história da Humanidade e em particular da ciência, estamos certos que o dia virá em que os povos reivindicarão para si o produto dos seus investimentos efetivos que fazem, através dos impostos que pagam, para o desenvolvimento dos novos medicamentos ou práticas terapêuticas que ainda só são de acesso a grupos restritos. É uma questão de direitos humanos, na nossa opinião.

Enquanto responsáveis pela edição de uma revista científica sentimo-nos legitimados para encorajar e até propor um novo olhar sobre as atuais práticas de oferta de serviços na saúde. Defendemos que o bem-estar coletivo se deve sobrepor à lógica de práticas que privilegiam a acumulação de mais-valias em detrimento daquele que deve ser um bem-maior: a condição humana e o direito à felicidade.

(c) EY-No Todo o conteúdo da revista Motricidade está licenciado sob a Creative Commons, exceto quando especificado em contrário e nos conteúdos retirados de outras fontes bibliográficas. 